\title{
Effect of oven residence time on mechanical properties in rotomoulding of LLDPE
}

\author{
P L RAMKUMAR*, SACHIN D WAIGAONKAR and D M KULKARNI \\ Department of Mechanical Engineering, BITS Pilani K K Birla Goa Campus, Zuari Nagar, Goa 403726, India \\ e-mail: plramkumarno1@gmail.com
}

MS received 27 March 2014; revised 12 August 2015; accepted 26 December 2015

\begin{abstract}
In rotational moulding of plastics, improving the mechanical properties without sacrificing the processibility is a challenging task. In this paper, an attempt has been made to investigate the effect of oven residence time on the mechanical properties of the rotationally moulded products made using linear low density polyethylene. Simulation studies were conducted using ROTOSIM software to analyze thermal transitions and phase changes during the process. Degree of curing of the polymers was also assessed and correlated with mechanical properties. Experiments were further conducted to obtain favourable oven residence time to obtain highest mechanical properties. Experimental investigation revealed that there exist regions where the part was 'under-cured' and mechanical properties were found to be inferior. It was also found that when parts were 'overcured', the mechanical properties were severely affected. A regime of favourable processing window was identified where the highest tensile, flexural and impact properties were noticed.
\end{abstract}

Keywords. Rotational moulding; oven residence time; LLDPE; mechanical properties; degree of curing; degradation.

\section{Introduction}

Rotational moulding is a polymer processing method used to produce hollow parts, usually of large volume. Since the polymer melt is not forced to take up a shape of the mould, the parts produced by this process are relatively stress-free as compared to other moulding processes like injection moulding or blow moulding. With proper product design, parts assembled from several pieces can be moulded as a single part (with no weld lines or joints), eliminating high fabrication and assembly costs. The products obtained from rotational moulding find extensive applications in various fields like agriculture, storage tanks, industrial equipment, medical devices, material handling, road/highways, and automobiles

Rotational moulding process is carried out in four different stages. These include charging the mould with thermoplastic powder [usually linear low density polyethylene (LLDPE), of around $500 \mu \mathrm{m}$ average particle size], heating and melting of the powder in a biaxial rotating mould, cooling of the mould and de-moulding of the part at slightly higher temperature than the ambient conditions [1-4]. The mechanical properties of rotationally moulded parts like tensile strength, impact strength, and flexural strength are the key measures of quality of the product. The mechanical properties in turn depend on

*For correspondence several process parameters like raw material [melt flow index (MFI), density, powder particle size, etc.], material of the mould, rotational speed and speed ratios of the mould, oven residence time, cooling time, pigments and additives. [5].

Crawford [5, 6], Crawford and James [4] identified the peak internal air temperature (PIAT) of LLDPE $\left(200-220^{\circ} \mathrm{C}\right)$ as one of the crucial factors to get the highest mechanical properties of the rotationally moulded product. Also, the structure-property-processibility studies of rotational moulding process have been extensively investigated by Crawford $[4,7]$. He also tested the rotomouldability of different resins like plastisols, polyethylene, polycarbonate, acetate butyrate, polyamide, elastomers, polyurethane, polypropylene, ethylene vinyl acetate, fluorocarbons and even polyamides. Out of these, LLDPE resins have the largest consumption in rotational moulding industry. It is due to their ideal melt flow property, broader processing window, excellent thermal stability and good mechanical properties. For PP/LLDPE blends, Run et al [8] revealed that the processing temperature greatly affects the mechanical properties, especially the ductility and the impact strength. Recently Aissa et al [9] have followed the motion of polymer powders inside a spherical mould to determine the effect of polymer powder particle size and distribution using graylevel co-occurrence matrix technique.

Ramkumar et al [10] have presented an extensive review on mechanical and fracture characterization of LLDPE. 
Sintering process of LLDPE has been investigated by Spence and Crawford [11]. The investigation revealed that increasing the number of fine particles causes formation of bubbles that were physically smaller, while larger particles increase the porous area in a product. Pick and Jones [12] found that metallocene-LLDPE (having a narrow molecular weight distribution than LLDPE) exhibit better impact properties than conventional LLDPE. Peroxides were used to obtain mouldings from LLDPE by chemical cross-linking of foams with uniform cell distribution and higher melt strength [13]. These were found to have good impact resistance, even at longer processing times.

Alejandro et al [14] have investigated the effect of prooxidant additive on LLDPE and LDPE and found complete loss of mechanical properties at different exposure times.

Waigaonkar et al [15] found that the cooling rate governs the crystalline morphology of the polymer which in turn governs the impact performance of the product.

Several researchers adopted simulations to understand the complex nature of heat transfer during the rotational moulding process. Antonio and Alfonso [1] used statistical and kinetic models for one-dimensional unsteady heat transfer during rotational moulding. Source based formulation was proposed by Banerjee et al [16] for modelling layer by layer non-isothermal deposition of plastic. The proposed method was also used for calculating the cycle time for particulate composites. A multimode crystallization kinetics model was suggested by Glomsaker et al [17] to correlate the crystallization with warpage. Recently, computer simulation based prediction of internal air temperature and degree of curing in multilayer rotational moulded parts was investigated by Alongkorn [18] using ROTOSIM simulation software.

In rotational moulding process, cycle time is observed as an important process parameter by the researcher which affects the quality of the product. Cycle time implies the total time spent by the polymer inside the oven (heating and cooling) till the complete product is demoulded. Tan et al [19] have found that the water cooling could be an effective alternative to reduce the cycle time in comparison with introduction of compressed air inside the mould as well as the use of $\mathrm{CO}_{2}$ at cryogenic conditions. According to the authors, cycle time has been reduced by using polyethylene of reduced molecular weight or melt viscosity. However, this can result in inferior impact strength [2]. Abdullah et al $[20,21]$ have reported a cycle time reductions of up to $70 \%$ with combination of different conditions like surface enhanced moulds, higher oven flow rates, internal mould pressure, and water spray cooling for cycle time reduction in rotational moulding. Liu and $\mathrm{Fu}$ [22] found that the mould surface enhanced with fins had faster heating and cooling rates and that triangular fin could be considered as a better choice from the manufacturing perspective. Several other innovative attempts have been made to reduce the cycle time, which include changing the thermal characteristics of the shell material [23], introducing internal pressure [24], and employing internal cooling [25].

From the above literature survey, it is evident that oven residence time is one of the most important process characteristics that govern the thermo-mechanical properties of the rotationally moulded product. As oven residence time is the time spent by the polymer inside the oven from room temperature till the oven is switched off, it also has deep impact on the productivity of the process. As rotational moulding process is mainly used to produce hollow products of larger dimensions the experimentation on industrial scale needs considerable resources and time, though the simulation studies are helpful in such situations very few of them take into account actual process conditions and their effect on mechanical properties of the product in their prediction. As a consequence, many times the prediction differs from the shop floor conditions. This paper deals with simulation and experimental studies to evaluate the effect of oven residence time on the mechanical properties of the rotationally moulded product. The simulation studies were initially conducted for different oven residence time and the extent of curing of the part was determined using ROTOSIM simulation software. The extent of curing, also referred as 'degree of curing', is a major factor in determining the mechanical properties of the component assessed using ROTOSIM. Experiments were further conducted to verify the predictions and obtain the conditions for favourable oven residence time to get the highest possible mechanical properties of the product.

\section{Simulation}

Rotational moulding process is characterized by the complex nature of heat transfer involving several phases and density changes of polymer. Moreover, the phase changes occur over a range of temperature. Further, due to the biaxial nature of mould rotation, there is a dearth of accurate thermal data measurement techniques and equipment at lesser cost [26]. This necessitates reliable prediction of critical timings of the process like switching off the oven and de-moulding time. The prediction can also economize the energy inputs to the processes and save significant energy as well as time. ROTOSIM software takes into account all the possibilities that exist in a typical rotational moulding process. Hence, the simulation studies were conducted using ROTOSIM.

ROTOSIM is a computer program for simulating the processes that occur in a rotational moulding cycle for polymers. It is based on a complex mathematical model of the major physical processes in the cycle. It enables the user to experiment with a variety of different operating conditions and observe the effects that these have on the resulting cycle conditions and the moulded product. During the simulation run, building up of a melt layer on the mould 
surface and development of solidified polymer layer can be observed. Temperature and phase change with respect to time are also generated by the simulation. The different aspects of the simulation are given below.

\subsection{Solid model of the mould and meshing}

For this study, a hollow product used as a plant vase has been selected which can be easily produced on a lab scale rotational moulding machine. An aluminium (Al) mould of $3 \mathrm{~mm}$ thickness has been considered, the shape of which resembles an inverted frustum of a cone. In order to have sufficient stiffness of the product, a minimal wall thickness of around $2 \mathrm{~mm}$ was designed. The part was initially modelled using Pro-E Wildfire software and meshing and analysis is done in ROTOSIM. The solid model of mould was meshed with triangular elements. Meshed model of the mould is as shown in figure 1.

\subsection{Material properties and process conditions}

In this study, LLDPE was considered for the purpose of simulation which was also utilized for experimental work. The mould and material properties are given in table 1 .

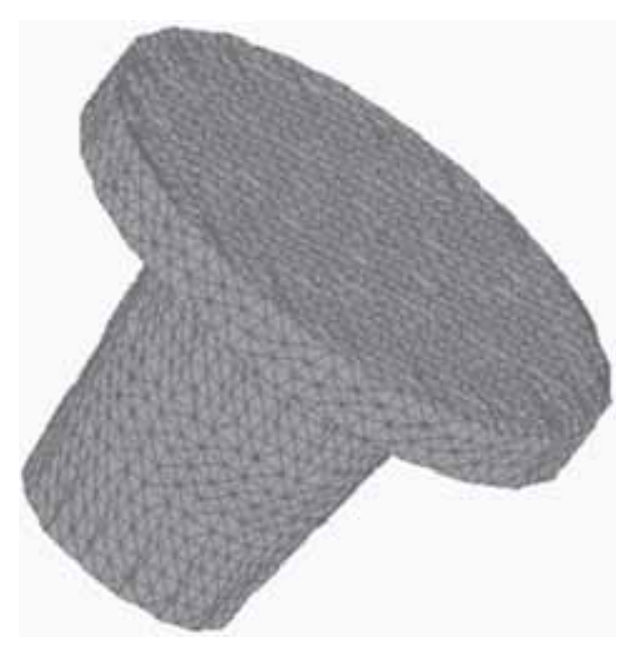

Figure 1. View of the meshed mould.
For rotational moulding process, a biaxial mould rotation was selected with the arm and plate speeds as $8 \mathrm{rpm}$ and $2 \mathrm{rpm}$ respectively, resulting in a major to minor axis ratio of 4:1, (which is considered to be ideal for getting uniform wall thickness) [5]. Initial conditions for simulation and experimentation were taken as $30^{\circ} \mathrm{C}$, while demoulding temperature was assumed as $50^{\circ} \mathrm{C}$.

For simulation studies, the temperature profile around the mould is an important input which must bear resemblance to the actual temperature around the mould. Thus, to correlate the findings with the experimental conditions, the mould temperature was measured (details given in section 3.2) and the mould environment profile was generated as shown in figure 2. This profile served as an input to ROTOSIM. The profile shows a time period of around $1680 \mathrm{~s}$ (almost $28 \mathrm{~min}$ ) to reach to peak set temperature of $220^{\circ} \mathrm{C}$. The temperature is held constant at $220^{\circ} \mathrm{C}$ from 1680 to $1780 \mathrm{~s}$ using ON-OFF relays as shown by the points $\mathrm{B}-\mathrm{C}$ in figure 2 . The oven residence time from 32 to 44 min has been considered in this study. In simulation, this can be realized as an increase in the length $\mathrm{B}-\mathrm{C}$ in figure 2 . The other features like speed reversal of the mould and internal cooling of the mould were not taken into account in this study. The outcomes of this simulation studies were compared with those obtained from experimental studies and discussed in the results and discussion.

\section{Experimental details}

\subsection{Materials}

For this study, LLDPE of grade R350 A 42, which has an MFI of $4.2 \mathrm{~g} / 10 \mathrm{~min}$ and a density of $935 \mathrm{~kg} / \mathrm{m}^{3}$ manufactured by Gas Authority India Limited (GAIL) was used. The average particle size of the powder was $500 \mu \mathrm{m}$ (around 35 mesh number). This grade is normally recommended for manufacturing of water storage tanks, automobile parts, boats, etc. The powder was already mixed with antioxidants and UV stabilizers, which turned its colour from natural to black. Based on the volume of the mould, powder shot weight of $0.6 \mathrm{~kg}$ was used in order to produce moulding with a wall thickness of about $2 \mathrm{~mm}$. The internal mould surface of the aluminium mould was coated with a silicone oil based mould release agent manually.

Table 1. Base case moulding conditions.

\begin{tabular}{|c|c|c|c|}
\hline Moulding condition & Mould (aluminum) & LLDPE & Air \\
\hline Thermal conductivity (W/m K) & 204 & 0.25 & 0.025 \\
\hline Specific heat of $(\mathrm{J} / \mathrm{kg} \mathrm{K})$ & 896 & 2600 & 1006 \\
\hline Density $\left(\mathrm{kg} / \mathrm{m}^{3}\right)$ & 2707 & 749.6 (melt) & 1.205 \\
\hline Internal convective heat transfer $\left(\mathrm{W} / \mathrm{m}^{2} \mathrm{~K}\right)$ & - & - & 5 \\
\hline External air convective heat $\left(\mathrm{W} / \mathrm{m}^{2} \mathrm{~K}\right)$ & - & - & 20 \\
\hline
\end{tabular}




\subsection{Machine and mould}

A lab scale electrically heated bi-axial rotational moulding machine was used as shown in figure 3. An aluminium hollow mould having the shape of an inverted frustum of cone was used for getting the desired product. This resembles to the solid model generated in section 2.1. A few preliminary experiments were initially conducted to decide the regime of oven residence time and assess the internal air temperature of the mould. In all the trials, oven

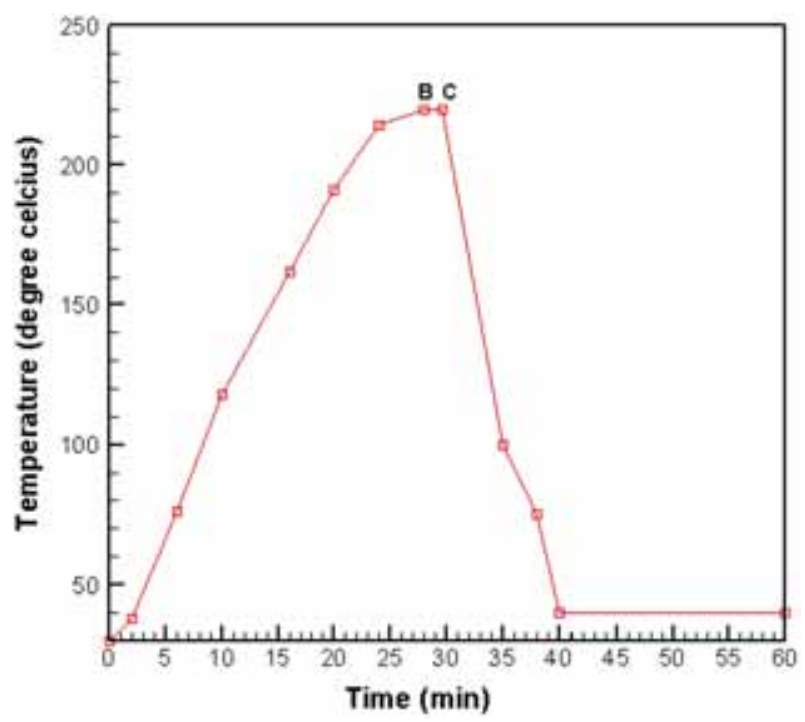

Figure 2. Typical mould environment profile. temperature was set at $220^{\circ} \mathrm{C}$. From the preliminary experiments, the oven residence time from 32 to $44 \mathrm{~min}$ was chosen as the active regime of experimentation. The internal air temperature was measured using a $\mathrm{K}$ type thermocouple considering uni-axial rotation of the mould as with this setup it is not possible to measure the same biaxially. It was confirmed that this temperature was sufficient to get a PIAT of $200^{\circ} \mathrm{C}$ in the above time regime.

During these experiments biaxial mould rotation was used with the arm (major axis) to plate (minor axis) speed ratio maintained at $4: 1$ to get consistent wall thickness. Table 2 gives details of the experimental set-up. With the chosen regime, experiments were conducted by altering the oven residence time and the product was obtained. The products were tested for mechanical properties in terms of tensile, flexural and impact strengths.

\subsection{Testing of mechanical properties}

The test specimens were prepared according to ASTM D 638 for tensile, ASTM D 790 for flexural and ASTM D 256 for impact testing respectively. CNC engraving machine was used to cut the required contour. Bench universal testing machine was used for tensile testing. Load cell of $14.7 \mathrm{kN}$ was used along with a crosshead speed of $5 \mathrm{~mm} /$ min. For the flexural testing, the load cell of $0-2.5 \mathrm{kN}$ was used and flexural strength at yielding was obtained. Impact tests were performed in typical Izod impact testing machine. A pendulum of maximum energy capacity of $4 \mathrm{~J}$ was used to evaluate the energy absorption ability of the

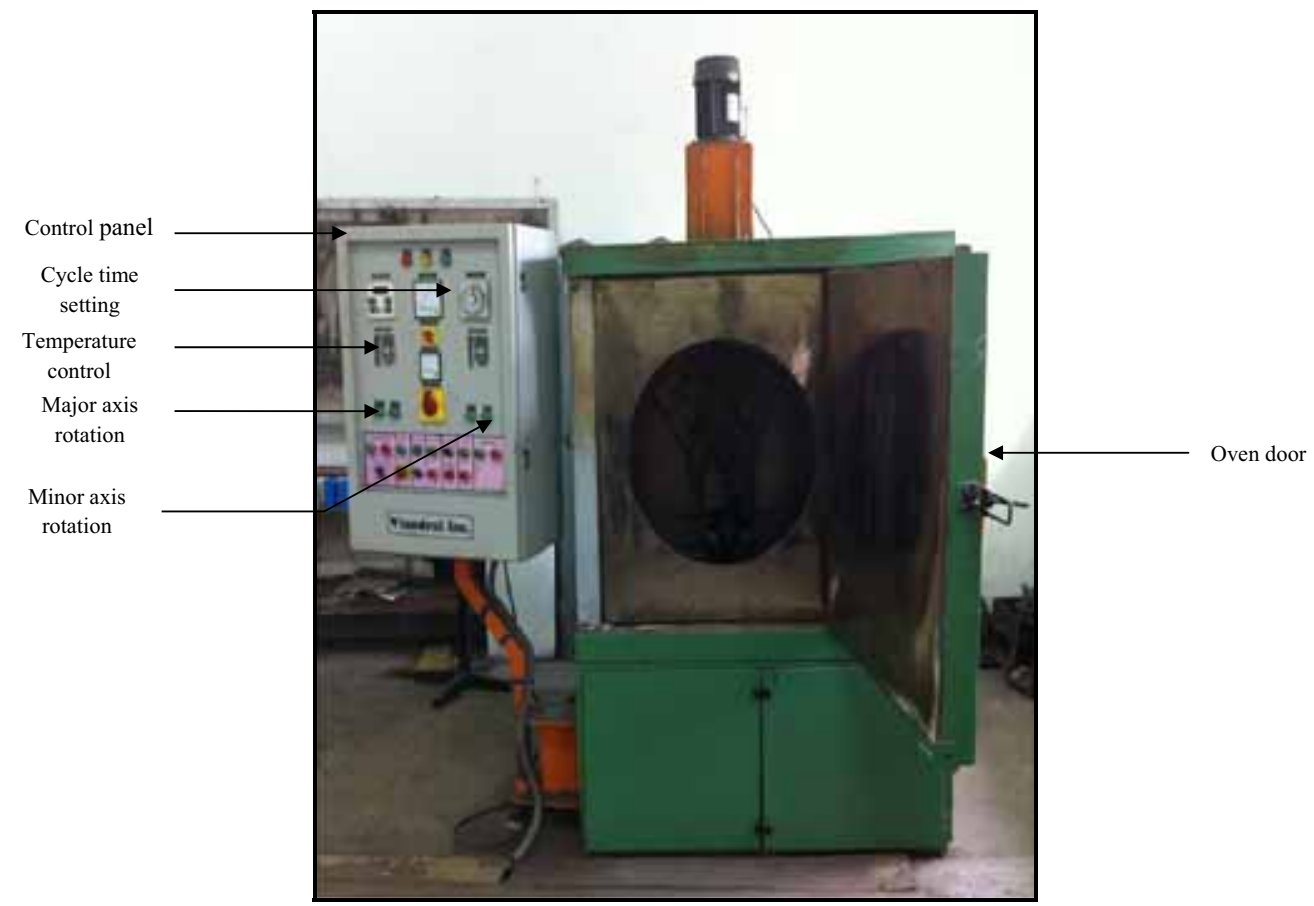

Figure 3. Biaxial rotational moulding machine. 
Table 2. Experimental setup used for the work.

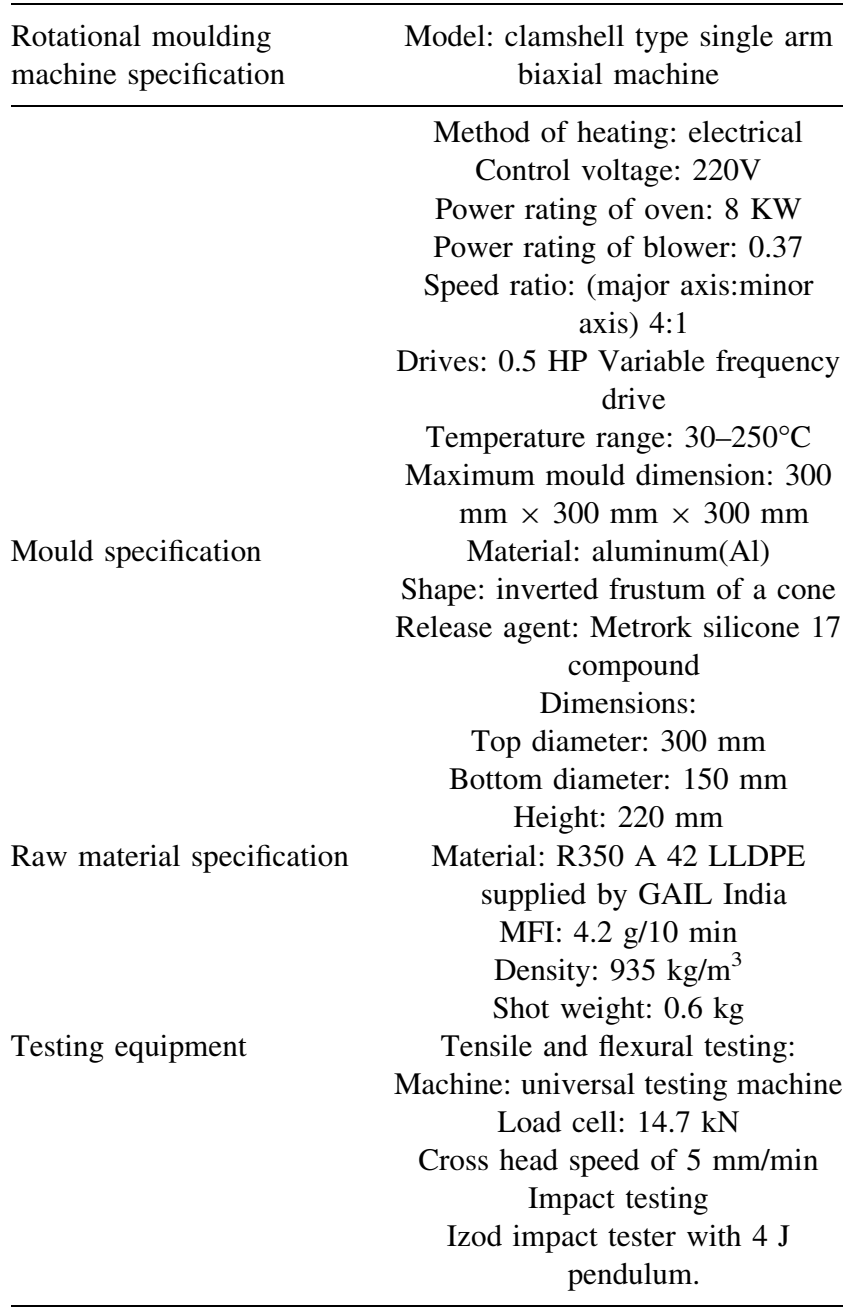

material. To account for process variability during experimentation, three replications were taken for each experimental run. Thus, three samples of each tensile, flexural and impact specimens were cut and subjected to testing.

Table 3 shows the plan of experiments, the value of tensile, impact and flexural strength obtained for different oven residence times.

\section{Results and discussion}

\subsection{Tensile strength}

The stress-strain plot for oven residence time of $38 \mathrm{~min}$ is as shown in figure 4 . The plot clearly reveals that elastic region at very low strains and significant plastic deformation are the characteristics of thermoplastic materials like LLDPE. The ultimate tensile strength was found as 17.4 MPa. Similarly, stress strain plot for all the oven residence time were recorded and the variation of tensile strength with respect to increase in oven residence time is shown in figure 5 . These results reveal that tensile strength gradually increases as the oven residence time increases from 32 to $40 \mathrm{~min}$ and falls after $40 \mathrm{~min}$. A closer look into the process gives more insight into this phenomenon. As the temperature increases from room temperature $\left(30^{\circ} \mathrm{C}\right)$, the powder inside the mould tumbles and when the temperature is above $120^{\circ} \mathrm{C}$ the powder starts sticking to the mould surface. With further increase in temperature, coalescence between the powder particles takes place and it becomes loose porous mass. In order to get the highest mechanical properties, the PIAT of the mould should reach $200^{\circ} \mathrm{C}$ as specified earlier. In the present case, though a PIAT of $200^{\circ} \mathrm{C}$ was achieved, the molten mass spent a short duration of time at and above $200^{\circ} \mathrm{C}$. This resulted in an incomplete fusion of the polymer particles resulting in a non-homogeneous structure, including entrapment of irregularly shaped air pockets. Therefore, it is obvious that the tensile strength was less between 32 and 34 min of oven residence time. This is referred as 'under-curing' and resulted in a weak product.

As the oven residence time was increased from 36 to $40 \mathrm{~min}$, the polymer melt spent sufficient time in the oven. Under this condition, the irregular pockets of trapped air transform into spheres. Most of the trapped spherical bubbles disappear and a complete coalescence with homogeneous structure is achieved. This region can be referred as 'completely cured' region and results in a good tensile strength of the product. Further, when the oven residence time was increased above $40 \mathrm{~min}$ the tensile strength of the product was decreased, as the degradation of the polymer

Table 3. Experimental run and corresponding outputs.

\begin{tabular}{lccc}
\hline Oven residence time $(\mathrm{min})$ & Average tensile strength $(\mathrm{MPa})$ & Average impact strength $(\mathrm{J})$ & Average flexural strength $(\mathrm{MPa})$ \\
\hline 32 & 16 & 0.52 & 18.2 \\
34 & 16.2 & 0.69 & 18 \\
36 & 17.2 & 0.92 & 17.6 \\
38 & 17.4 & 0.97 & 17 \\
40 & 17.4 & 1 & 17.2 \\
42 & 16 & 0.8 & 16.7 \\
44 & 15.3 & 0.6 & 16.0 \\
\hline
\end{tabular}


was noticed at this stage. This is referred as 'over-cured' and results in a partially burnt product.

In order to correlate the mechanical behaviour of LLDPE with that of oven residence time, differential scanning calorimetry (DSC) was performed to characterize the material with a steady temperature rate of $10^{\circ} \mathrm{C} / \mathrm{min}$. The DSC graph is as shown in figure 6. It shows an endothermic peak at $124^{\circ} \mathrm{C}$ revealing melting of LLDPE. The material shows excellent thermal stability after melting till a temperature of $249^{\circ} \mathrm{C}$. The exothermic peak at $249^{\circ} \mathrm{C}$ shows the commencement of degradation of the polymer. The peaks after $400^{\circ} \mathrm{C}$ indicate complete burning of LLDPE including additives. Since the oven heating rate in the rotational moulding set-up is about $5^{\circ} \mathrm{C} / \mathrm{min}$, the

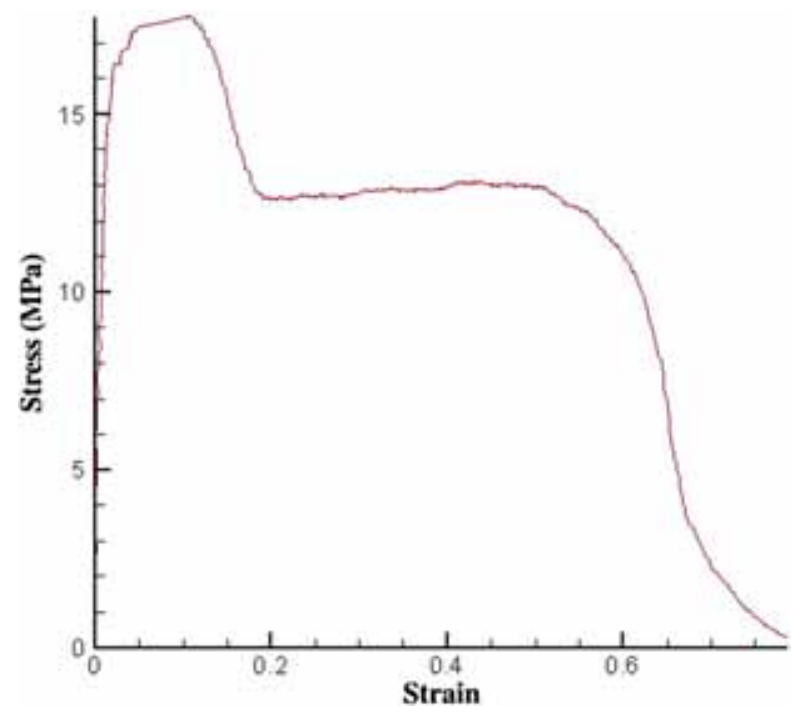

Figure 4. Stress strain plot for oven residence time $38 \mathrm{~min}$.

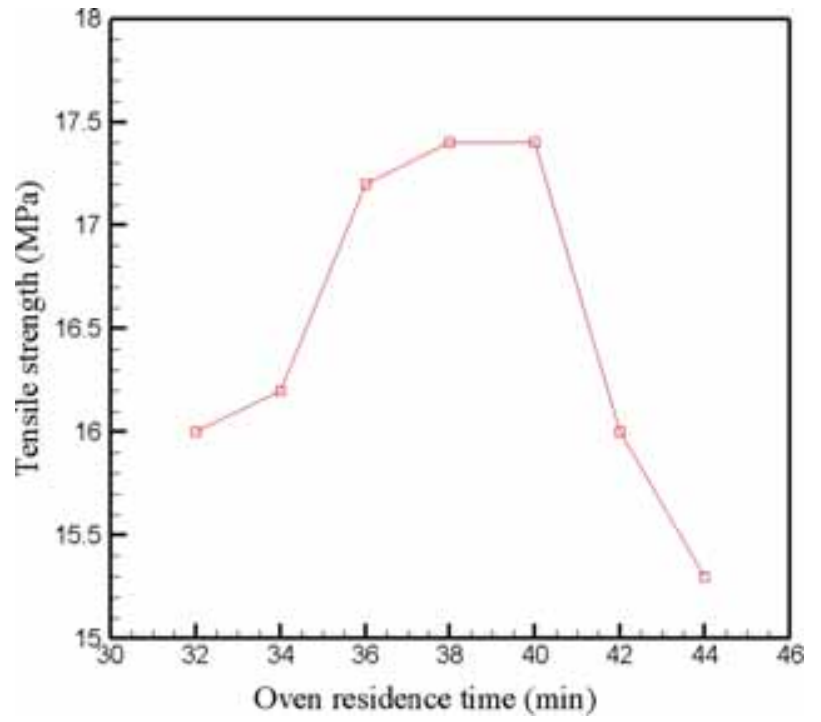

Figure 5. Variation of tensile strength with respect to cycle time.

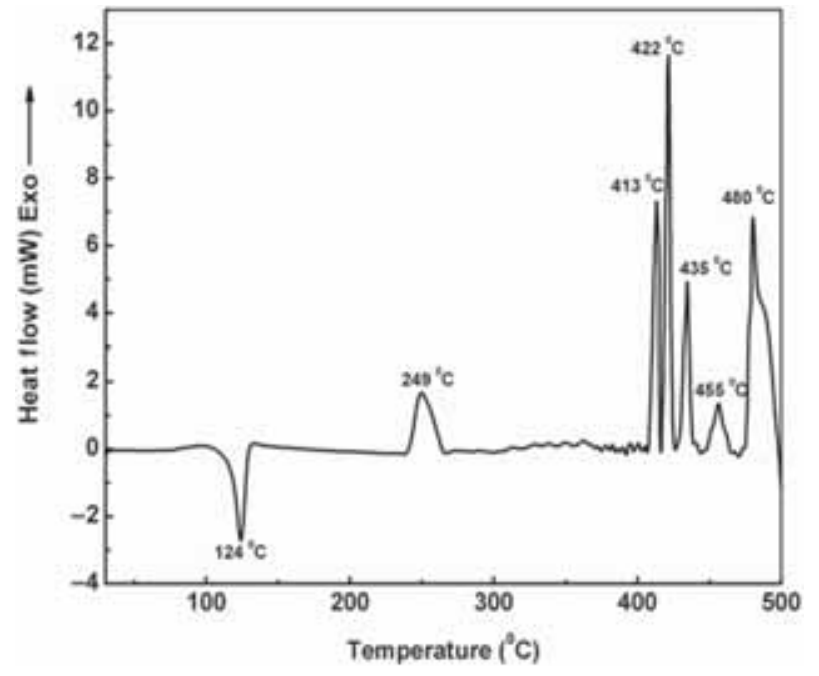

Figure 6. Differential scanning calorimeter (DSC) trace for LLDPE.

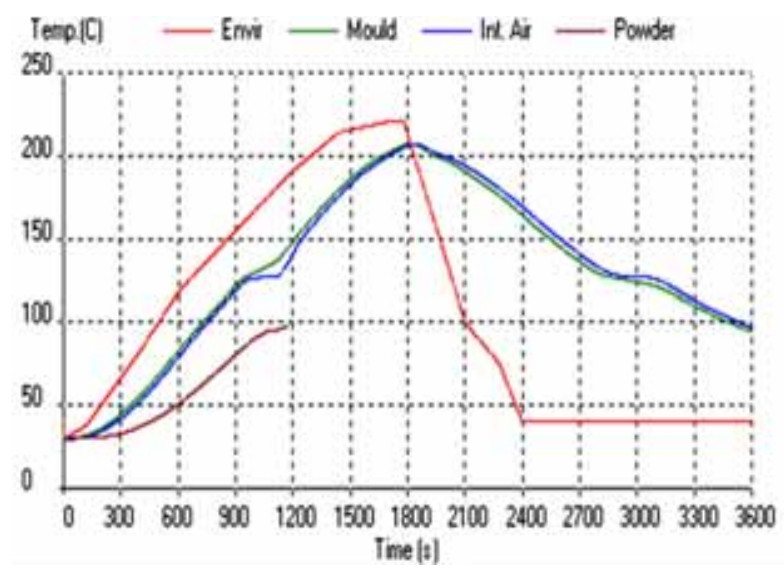

Figure 7. Temperature plot for $32 \mathrm{~min}$.

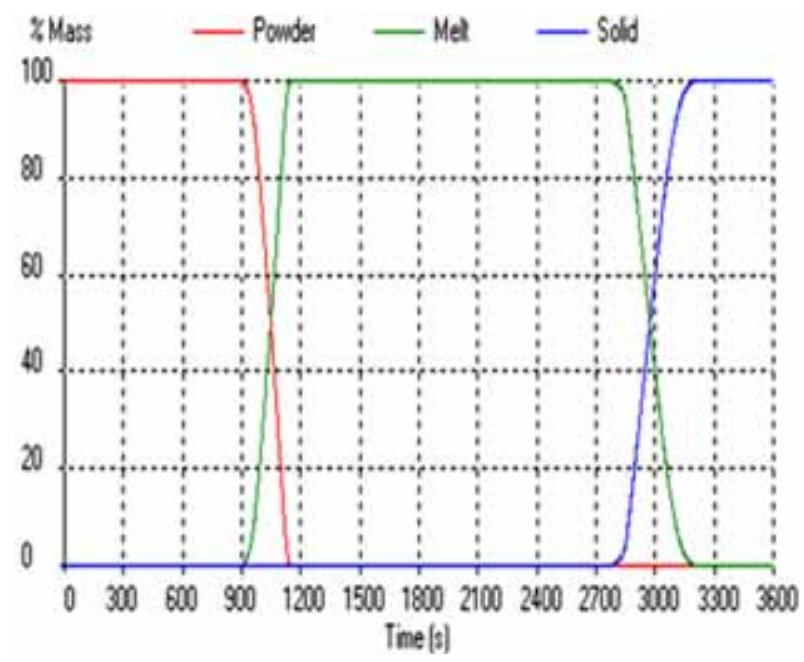

Figure 8. Polymer phase transitions plot for $32 \mathrm{~min}$. 


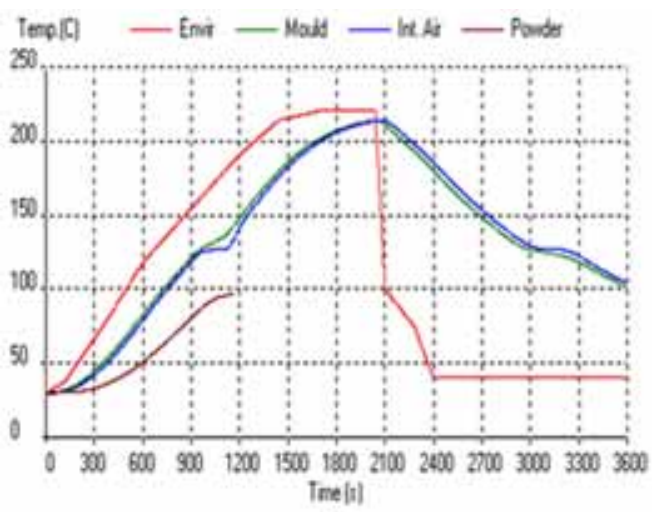

(a)

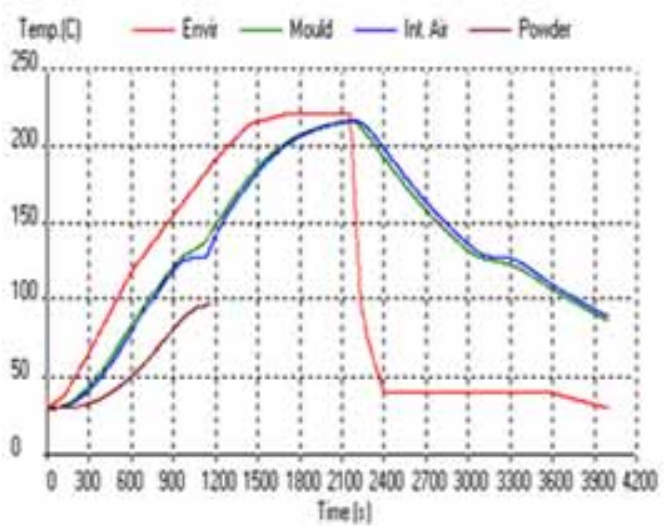

(c)

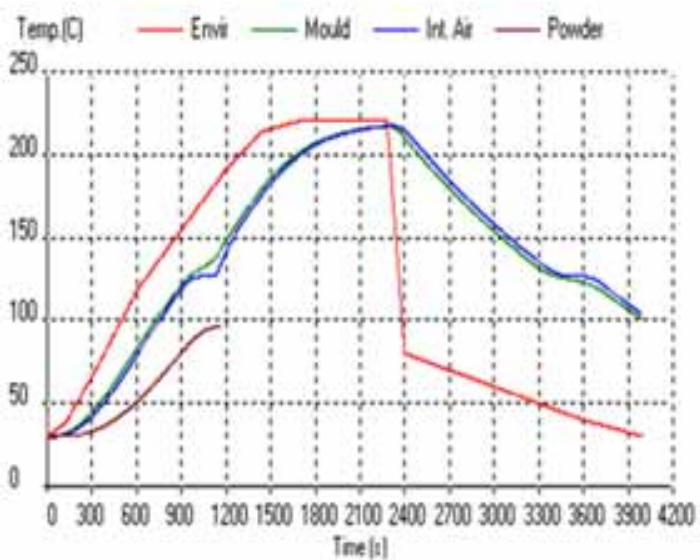

(e)

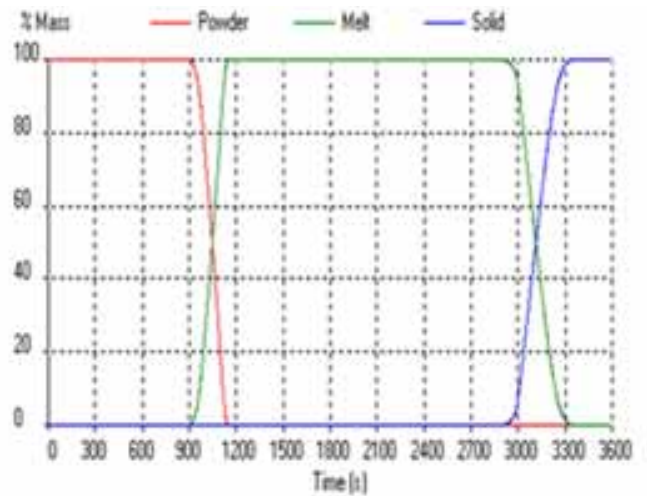

(b)

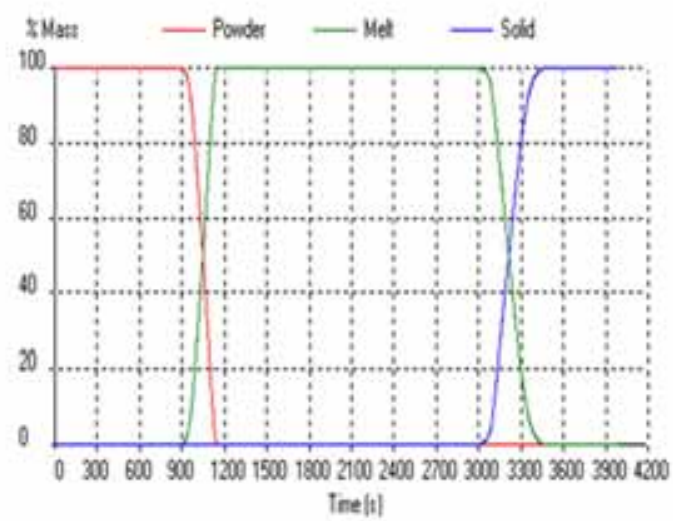

(d)

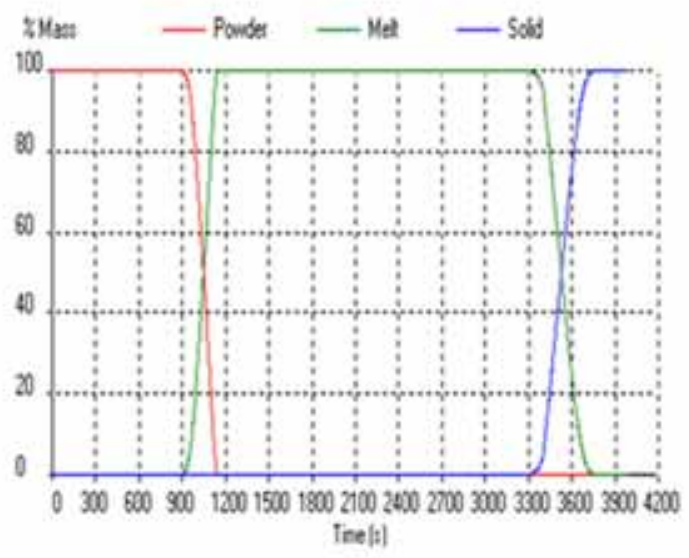

(f)

Figure 9. (a) Temperature plots for $34 \mathrm{~min}$, (b) polymer phase transitions plot for $34 \mathrm{~min}$, (c) temperature plots for 36 min, (d) polymer phase transitions plot for $36 \mathrm{~min}$, (e) temperature plots for $38 \mathrm{~min}$, (f) polymer phase transitions plot for 38 min, (g) temperature plots for $40 \mathrm{~min}$, (h) polymer phase transitions plot for $40 \mathrm{~min}$, (i) temperature plots for 42 min and (j) polymer phase transitions plot for $42 \mathrm{~min}$.

decomposition temperature of polymer is realized after $40 \mathrm{~min}$. This resulted in a decrease in tensile strength of the product.

The simulation studies conducted in section 2 provide further insight into the transient temperature distribution inside the mould, which can be correlated with the mechanical properties of the product. The transient temperature distribution of the process is shown in figure 7, while the polymer phase change plot is depicted in figure 8 for $32 \mathrm{~min}$ of oven residence time. From these plots, the time lag due to convective heating from oven (environment) to the mould can be clearly seen. The internal air 


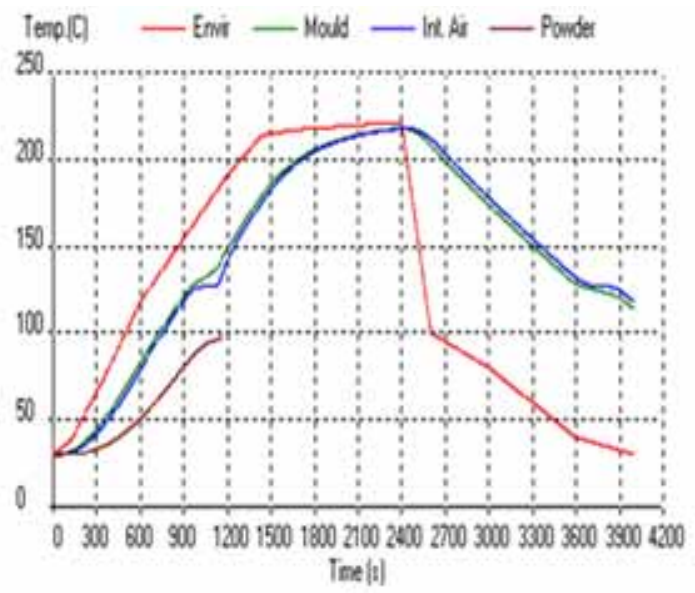

(g)

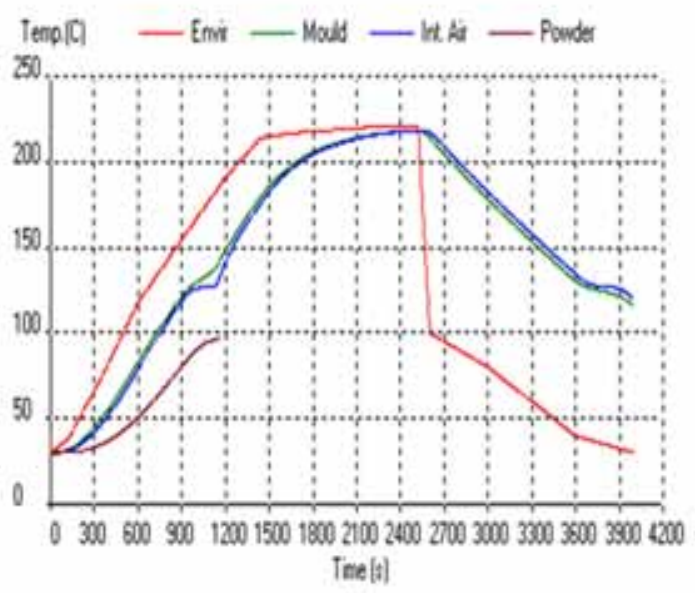

(i)

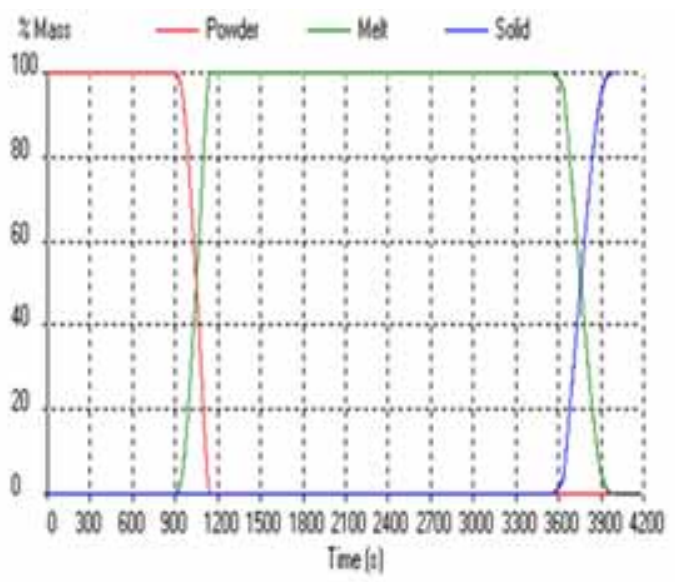

(h)

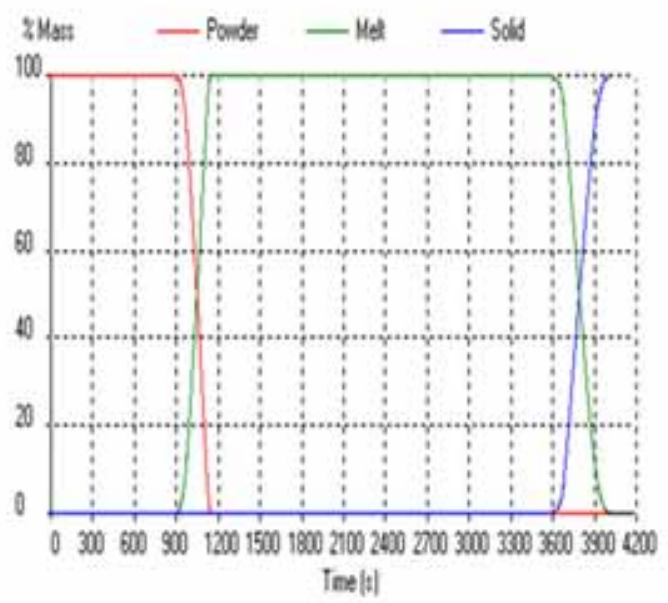

(j)

Figure 9. continued

temperature plot (IAT) follows the phase changes in LLDPE. For example, in figure 7 , we can notice a horizontal line at around $124^{\circ} \mathrm{C}(15 \mathrm{~min})$, indicating the phase change of the polymer from the powder to the melt. This can also be seen from the phase change plots of the polymer as shown in figure 8 . At $15 \mathrm{~min}$ the polymer starts converting into melt thereby increasing its mass fraction. At the same time, since the powder is being converted into melt, its mass fraction decreases. It can be noticed from figure 8 that at around $20 \mathrm{~min}$ all the powder gets converted into melt and thereafter polymer remains in the molten state. From figure 7, it can be seen that even after switching off the oven at $30 \mathrm{~min}\left(220^{\circ} \mathrm{C}\right)$, the IAT keeps on rising and it reaches $200^{\circ} \mathrm{C}$ which is a PIAT of the polymer processed. At $45 \mathrm{~min}$, the molten LLDPE again starts losing the latent heat of fusion and gets converted into solid phase. Thus, complete solidification occurs at around 53 min (100\% solid, $0 \%$ melt) as evident from figure 8 . Therefore, we could notice from this simulation that PIAT of $200^{\circ} \mathrm{C}$ could be reached in this setting, which was generally considered as a healthy sign to get better mechanical properties of rotaionaly moulded products. However, LLDPE has spent around $3.5 \mathrm{~min}$ (1750-1950 s) at this temperature, which has caused under curing of the product, resulting in lower tensile properties.

Simulations were further continued by varying the oven residence times starting from $32 \mathrm{~min}$ to 44 min keeping other parameters constant. The temperature and polymer phase transitions plots of these are as shown in figure 9(aj). We can observe that for $34 \mathrm{~min}$, the molten mass is above PIAT of $200^{\circ} \mathrm{C}$ for $5.8 \mathrm{~min}$, for $36 \mathrm{~min}$ it is $8.3 \mathrm{~min}$, for $38 \mathrm{~min}$ it is $9.1 \mathrm{~min}$, for $40 \mathrm{~min}$ it is $11.6 \mathrm{~min}$, for $42 \mathrm{~min}$ it is $13.3 \mathrm{~min}$ and so on. In order to represent the extent of time which LLDPE has spent above the melting temperature, time-temperature curves are plotted. These are referred as degree of curing plot. Degree of curing is the time that polymer powder spends in the oven above its melting temperature $\left(125^{\circ} \mathrm{C}\right.$ in the present case). Thus, higher the degree of curing better is the chances for dissolution of bubbles and getting a sound product. Degree of 


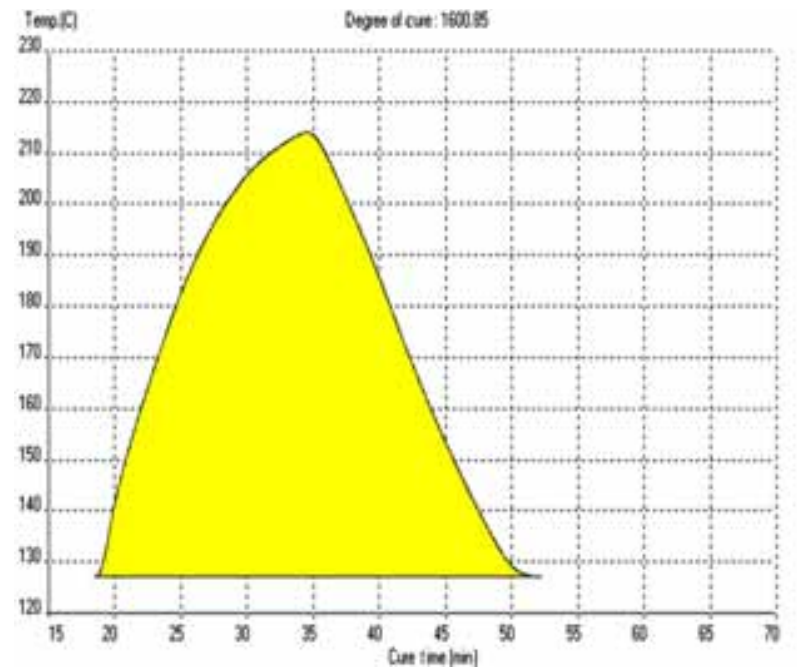

Figure 10. Degree of curing plot for $38 \mathrm{~min}$.

curing plot for oven residence time of $38 \mathrm{~min}$ is as shown in figure 10 for reference. Similarly, degree of curing plot can be generated for different oven residence time using simulation, from the simulation it is observed that higher degree of curing is achieved when the oven residence time is increased. Theoretically, though the higher degree of cooling means better mechanical properties, polymer degradation starts beyond a specific temperature $\left(249^{\circ} \mathrm{C}\right.$, as confirmed by DSC), which results in reduction in mechanical properties. The results summarized in table 4 clearly indicate the influence of oven residence time, degree of curing and time for which the material is above $200^{\circ} \mathrm{C}$ on the tensile and flexural strengths of LLDPE. Thus, it can be concluded that not only PIAT but also the time that the polymer spends above the PIAT governs the mechanical properties of the rotationally moulded products.

\subsection{Flexural strength}

The results of flexural testing are shown in figure 11. These results reveal that the flexural strength of the product decreases as the oven residence time increases from 32 to $38 \mathrm{~min}$. It can be attributed to the incomplete coalescence

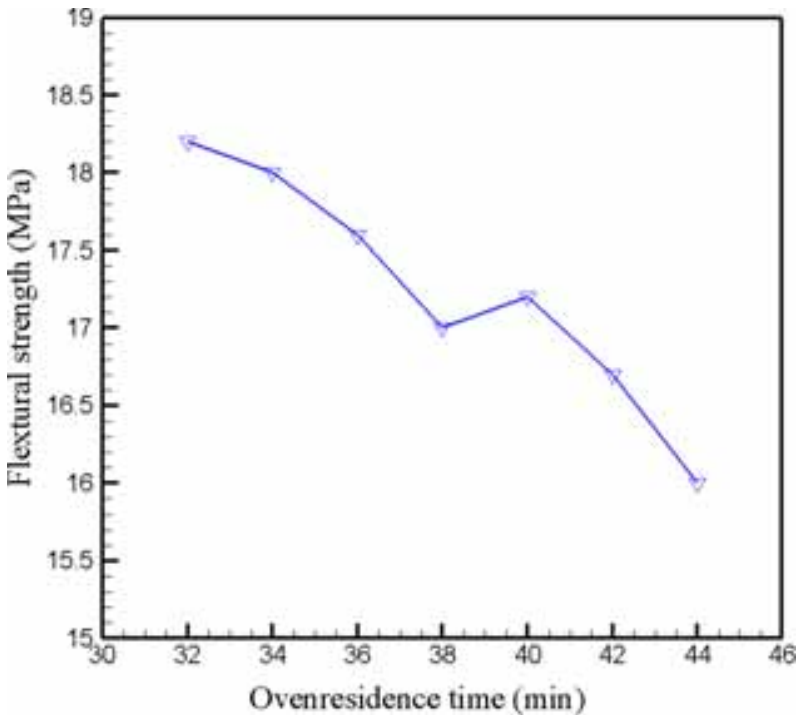

Figure 11. Variation of flexural strength with respect to cycle time.

of powder particle. Such a part can have entrapped bubbles, leading to reduction in flexural strength. With the further increase in oven residence time from 38 to $40 \mathrm{~min}$, the entrapped bubbles may escape owing to reduction in polymer melt viscosity thereby increasing the flexural strength. Beyond $40 \mathrm{~min}$, the product is subjected to oxidation and it becomes brittle. Therefore, the flexural strength is further reduced.

\subsection{Impact strength}

Variation of impact strength with respect to the oven residence time is as shown in figure 12. It can be seen that, the impact properties of the rotationally moulded product follow a similar trend like tensile properties. The increase in impact strength from 32 to $38 \mathrm{~min}$ of oven residence time can be attributed to the formation of small spherulites that grow sufficiently larger and get bonded with neighbouring particles. During this stage of polymer sintering, the pockets of air are entrapped in the melt because of the high viscosity of the polymer melt. With further increase in temperature the pressure inside such air pockets increases,

Table 4. Influence of oven residence time and degree of curing on tensile and flexural strength.

\begin{tabular}{lccccc}
\hline $\begin{array}{l}\text { S. } \\
\text { no. }\end{array}$ & $\begin{array}{c}\text { Oven residence time in } \\
\text { min }\end{array}$ & $\begin{array}{c}\text { Degree of curing in }{ }^{\circ} \mathrm{C}- \\
\min \end{array}$ & $\begin{array}{c}\text { Curing time in sec above } \\
200^{\circ} \mathrm{C}\end{array}$ & $\begin{array}{c}\text { Tensile strength in } \\
\mathrm{MPa}\end{array}$ & $\begin{array}{c}\text { Flexural strength in } \\
\mathrm{MPa}\end{array}$ \\
\hline 1 & 32 & 1340.56 & 300 & 16 & 18.2 \\
2 & 34 & 1600.85 & 350 & 16.2 & 18 \\
3 & 36 & 1761.95 & 500 & 17.2 & 17.4 \\
4 & 38 & 2088.51 & 550 & 17.4 & 17 \\
5 & 40 & 2414.14 & 700 & 16 & 16.2 \\
6 & 42 & 2494.90 & 800 & & 16.7 \\
\hline
\end{tabular}


thereby reducing their diameter. Such bubbles start escaping through the surface. As a result, the number of bubbles starts diminishing and can be seen in the form of increase in part density and improved impact strength.

With the above findings, it is possible to summarize the variation of mechanical properties with respect to the oven residence time as shown in figure 13. Based on the values of the mechanical properties a favourable processing window can be suggested that lies between 36 and $40 \mathrm{~min}$ (region between two vertical lines) where the highest

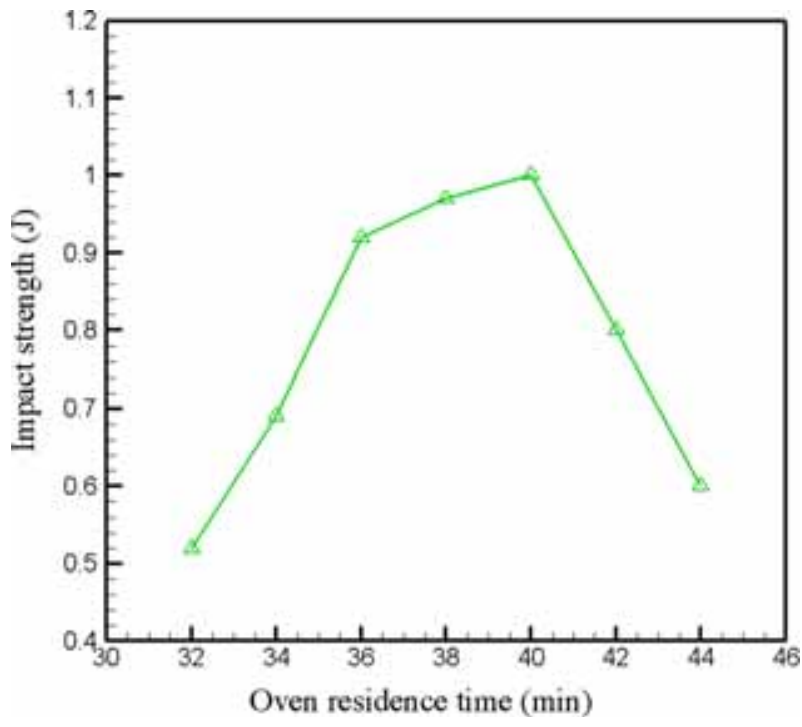

Figure 12. Variation of impact strength with respect to cycle time. mechanical properties were obtained. Below and over these values, the quality of products obtained was inferior.

\subsection{Verification experiments}

Upon selecting the regime of favourable processing window (oven residence time between 36 and $40 \mathrm{~min}$ ), confirmatory experiments were performed. Three replicates were obtained for each of three oven residence time. The results of the confirmatory experiments are shown in table 5. It could be seen that the values of tensile, impact and flexural remain to their highest values under the selected process conditions.

\section{Conclusions}

In this paper, the effect of oven residence time on the mechanical properties of rotationally moulded LLDPE products was investigated. Experiments were conducted on a laboratory scale rotational moulding machine by varying the oven residence timings from 32 to $44 \mathrm{~min}$. The products were tested for tensile, flexural and impact strengths according to ASTM standards. It was observed that all the above properties showed an increased trend from 32 to $40 \mathrm{~min}$. This can be attributed to the formation of a homogeneous melt due to escapement of entrapped air pockets with increase in temperature. One important observation was that the PIAT of $200^{\circ} \mathrm{C}$ was not only important factor, but also the time the polymer spends beyond this temperature is also crucial in governing the

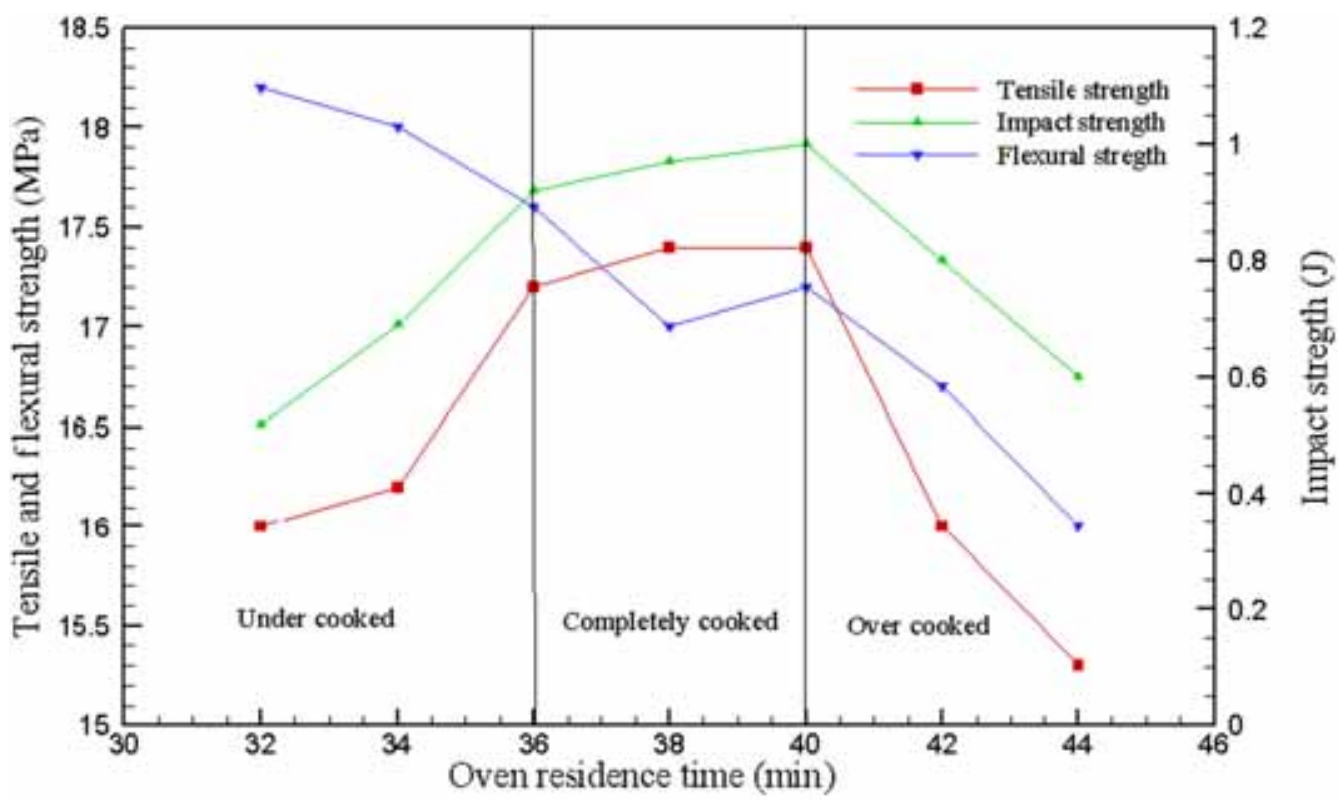

Figure 13. Processing windows for LLDPE product (thickness $3 \mathrm{~mm}$ ) processed in an aluminium mould. 
Table 5. Verification experiments.

\begin{tabular}{|c|c|c|c|c|c|c|c|}
\hline $\begin{array}{l}\text { Trial } \\
\text { no }\end{array}$ & $\begin{array}{l}\text { Oven residence } \\
\text { time (min) }\end{array}$ & $\begin{array}{c}\text { Tensile } \\
\text { strength } \\
(\mathrm{MPa})\end{array}$ & $\begin{array}{l}\text { Average tensile } \\
\text { strength }(\mathrm{MPa})\end{array}$ & $\begin{array}{c}\text { Impact } \\
\text { strength }(\mathrm{J})\end{array}$ & $\begin{array}{l}\text { Average impact } \\
\text { strength }(\mathrm{J})\end{array}$ & $\begin{array}{c}\text { Flexural } \\
\text { strength } \\
(\mathrm{MPa})\end{array}$ & $\begin{array}{l}\text { Average flexural } \\
\text { strength (MPa) }\end{array}$ \\
\hline 1 & 36 & 17.4 & 17.4 & 0.92 & 0.94 & 17.2 & 17.1 \\
\hline 2 & & 17.4 & & 0.94 & & 16.9 & \\
\hline 3 & & 17.6 & & 0.96 & & 17.4 & \\
\hline 4 & 38 & 17.6 & 17.6 & 0.94 & 0.96 & 17 & 16.9 \\
\hline 5 & & 17.6 & & 1 & & 15.5 & \\
\hline 6 & & 17.8 & & 0.96 & & 18.2 & \\
\hline 7 & 40 & 17.6 & 17.4 & 1.1 & 1 & 17.2 & 17 \\
\hline 8 & & 17.4 & & 0.92 & & 17.2 & \\
\hline 9 & & 17.4 & & 1 & & 16.8 & \\
\hline
\end{tabular}

mechanical properties. Simulation studies were conducted to analyze the different thermal transitions along with phase changes and the degree of curing of the polymers was assessed. This is correlated with the mechanical properties. It was also observed that the mechanical properties were reduced beyond $40 \mathrm{~min}$ of oven residence time, though theoretically high degree of curing was obtained. This can be attributed to the degradation of the polymer which was confirmed by conducting DSC studies. Thus, a regime of favourable processing window was obtained between 36 and $40 \mathrm{~min}$ where the maximum tensile strength of 17.4 MPa, flexural strength of $17.1 \mathrm{MPa}$ and impact strength of $1 \mathrm{~J}$ was noticed.

It should be emphasized here that on an industrial scale, the rotational moulding machines take very less time to reach the set temperature (around $220^{\circ} \mathrm{C}$ ) due to the presence of high capacity gas (or diesel) burners. As in our case an electrically heated oven was used, more time was needed for the oven to reach the preset temperature of $220^{\circ} \mathrm{C}$. This can be regarded as one of the practical limitations of this study. The factors like rotational speed ratio, cooling rate also contribute to the above properties. With increase in thickness, the issues like warpage of the part need to be addressed separately. However, similar studies can be conducted on an industrial scale and correlated with simulation studies. The correlation of simulation and experimental studies provide new insight of process control that can be extended to polymers like Polypropylene and ABS having a narrow processing window but excellent mechanical properties.

\section{References}

[1] Antonio G and Alfonso M 2004 Powder shape Analysis and sintering behavior of high-density polyethylene powders for rotational molding. J. Appl. Polym. Sci. 92: 449-460

[2] Bharat I C, Elizabeth T and John V 2001 Processing enhancers for rotational molding of polyethylene. Polym. Eng. Sci. 41: 1731-1742
[3] Brent Strong A 2006 Plastics materials and processing. 3rd edn, New jersey, United States: Pearson Education Inc

[4] Crawford R J and James L T 2002 Rotational molding technology. England Norwich: William Andrew Publishing

[5] Crawford R J 1996 Recent advances in the manufacture of plastic products by rotomoulding. J. Mater. Process. Technol. 56: 263-271

[6] Crawford R J 2003 Vision 2020 through 2002. Rotation. 12: $16-19$

[7] Crawford R J 1994 Causes and cures of problems during rotomoulding. Rotation 3: 10-14

[8] Run SU, Wang K E, Qin Zhang, Feng Chen and Qiang Fu 2010 Effect of melt temperature on the phase morphology, thermal behavior and mechanical properties of injectionmolded PP/LLDPE blends. Chinese J. Polym. Sci. 28: 249-255

[9] Amara Aissa, Carl Duchesne and Denis Rodrigue 2012 Characterization of polymer powder motion in a spherical mold in biaxial rotation. Polym. Eng. Sci. 954-963

[10] Ramkumar P L, Kulkarni D M and Chaudhari V V 2014 Parametric and mechanical characterization of linear low density polyethylene (LLDPE) using rotational moulding technology. Sadhana - Acad. Proc. Eng. Sci. 39: 625-635

[11] Spence A G and Crawford R J 1996 The effect of processing variables on the formation and removal of bubbles in rotationally moulded products. Polym. Eng. Sci. 36: 993-1009

[12] Louise Therese Pick and Eileen Harkin-Jones 2003 An investigation in to relationship between the impact performance of rotationally moulded polyethylene products and their dynamic mechanical properties. Polym. Eng. Sci. 43: 905-918

[13] Marcilla A and Garcia-Quesada J C 2007 Cross linking of rotational molding foams of polyethylene. Polym. Eng. Sci. 47: $1804-1812$

[14] Alejandro Benítez, Sanchez J J, Arnal L M and Mülle A 2013 Abiotic degradation of LDPE and LLDPE formulated with a pro-oxidant additive. Polym. Degrad. Stabil. 98: 490-501

[15] Sachin Waigaonkar, Babu B J C and Amit Rajput 2011 A case study of rotational moulding process. Int. J. Six Sigma Compet. Advant. 6: 256-277

[16] Banerjee S, Yan W and Bhattacharyya D 2008 Modeling of heat transfer in rotational molding. Polym. Eng. Sci. 48: 2188-2197 
[17] Glomsaker T, Hinrichsen E L, Larsen A, Doshev P and Ommundsen E 2009 Warpage - Crystallinity relations in rotational molding of polypropylene. Polym. Eng. Sci. 49: 523-530

[18] Alongkorn Kanokboriboon 2009 Computer simulation and internal air temperature assist in moulding multi-layer rotationaly moulded parts. Rotation. 5: 66-71

[19] Tan S B, Hornsby P R, McAfee M B, Kearns M P and McCourt M P 2011 Internal cooling in rotational moldingA review. Polym. Eng. Sci. 51: 1683-1692

[20] Abdullah M Z, Bickerton S and Bhattacharyya D 2007 Rotational molding cycle time reduction through surface enhanced molds: Part A-Theoretical study. Polym. Eng. Sci. 47: 1406-1419

[21] Abdullah M Z, Bickerton S, Bhattacharyya D, Crawford R J and Harkin-Jones E 2009 Rotational moulding cycle time reduction using combination of physical techniques. Polym. Eng. Sci. 49: 954-963
[22] Liu S J and Fu K H 2008 Experimental investigation and numerical simulation of the heating/cooling process in rotational molding enhanced with fins. J. Appl. Polym. Sci. 108: 1696-1705

[23] Yan W, Lin R J T, Bickerton S and Bhattacharya D 2003 Rotational moulding of particle reinforced polymeric shell structures. Mater. Sci. Forum 235-238

[24] Crawford R J, Spence A G, Cramez M C and Oliveira M J 2004 Mold pressure control as a tool in rotational molding. Proc. Inst. Mech. Eng. B - J. Eng. 218: 1683-1694

[25] Khouri R M 2004 Reducing cycle time in rotational moulding of plastics. $\mathrm{PhD}$ thesis, Queens University of Belfast UK

[26] Crawford R J and Nugent P J 1992 A new process control system for rotational moulding. J. Plast. Rubber Compos. Process. Appl. 7: 23-27 